IJPDLM

43,7

564

Received 6 May 2012

Revised 25 June 2012

25 August 2012

27 October 2012

1 November 2012

Accepted 6 November 2012

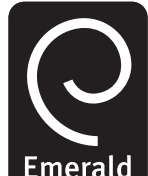

International Journal of Physical Distribution \& Logistics Management Vol. 43 No. 7,2013

pp. $564-585$

(C) Emerald Group Publishing Limited 0960-0035

DOI 10.1108/IJPDLM-04-2012-0132

\section{Impact of reverse logistics on supply chain performance}

\author{
Mario Turrisi and Manfredi Bruccoleri
}

Department of Chemical, Management, Software and Mechanical Engineering, University of Palermo, Palermo, Italy, and

Salvatore Cannella

Centre for Management Studies, Technical University of Lisbon, Lisbon, Portugal

\begin{abstract}
Purpose - The purpose of this paper is to analyse the impact of reverse logistics on order and inventory variance amplification in a single-echelon supply chain (SC) and to propose a new order policy for dampening such amplification.
\end{abstract}

Design/methodology/approach - A general review of the literature on sustainable operations and on the impact of reverse logistics on SC performance provides the foundation for the study. The authors use difference equation math approach for modelling and analysing a closed SC. A proper design of experiment and data collected from the European Union statistics validate the obtained numerical results.

Findings - The variability of reverse flow in a closed loop SC increases the serviceable inventory variance. However, a proper design of the reverse flow considerably improves the global performance. To this purpose, the authors propose a new order policy, namely R-APIOBPCS, which explicitly considers the reverse flow of products.

Research limitations/implications - The paper presents a math model describing a closed loop supply chain (CLSC). No empirical analysis is provided. Future researches should evaluate the impact of the proposed R-APIOBPCS on more realistic closed loop SC models.

Practical implications - The paper's findings may motivate logistics and SC managers to implement CLSC when supported by innovative, suitable tools for the proper management of the information and material flow in the chain. Managers should be well acquainted that, by doing so, they not only satisfy national and international legislations but also achieve improvements in logistics performance.

Originality/value - The authors propose a novel replenishment rule that accurately coordinates the upstream and downstream flows in a SC. The proposed order policy can be reasonably considered one of the advocated managerial tools for the proper management of reverse logistics: it allows reducing inventory and limiting the variability of the orders placed to suppliers in SC with reverse logistics.

Keywords Supply chain management, Logistics management, Sustainability, Reverse logistics, Closed-loop supply chain, Bullwhip effect

Paper type Research paper

\section{Introduction}

The concept of sustainability is of growing interest in the last two decades among policy makers, the popular press and scientific journals in various technical fields (Linton et al., 2007). The scarcity of resources, problems with pollution caused by industrialized countries (Tahvonen, 2000) and the environmental, social and economic uncertainty of recent years (Schneider et al., 2010) have led many researchers to address the issue of sustainable development from many points of view. European Union (EU) legislation has highlighted the importance of products recovery and recycling. Different directives have 
been released in the last ten years for regulating waste management policies. From an operations management point of view, closed-loop supply chains (CLSCs) represent one of the main supply chain (SC) structures that received great interest from both industry and academic worlds. Research on reverse logistics and CLSCs is considerably increasing because tightly linked with industrial ecology (Adenso-Díaz et al., 2012; Carter and Easton, 2011; Mollenkopf et al., 2011; Georgiadis and Besiou, 2010; Nasr and Thurston, 2006; Rubio et al., 2008) and the development of new strategies (Skinner et al., 2008). Products recovery and reuse reduce the negative effects on environment, mainly reducing waste disposal, extraction of raw materials and transport and distribution emissions. Furthermore, firms can recover value from end-of-life products by reusing components, recycling materials or recovering energy through incineration (Kleindorfer et al., 2005). Finally, reverse logistics practices can reduce the customer's risk when buying a product, and increase the customer value (Russo and Cardinali, 2012; Rogers and Tibben-Lembke, 2001). However, the success of reverse logistics implementation requires the coordination of forward and backward flows of both materials and information (Guide and Van Wassenhove, 2002). The reverse flow of products entering the chain impacts the dynamics of SC members' inventories. This, in turns, affects the dynamics of order placed to suppliers and, thus, impacts the performance of the entire SC in terms of the order and inventory variance amplification. Thus, although reverse logistics may bring benefits in terms of economic and green sustainability, and also customer values, SC managers could still be reluctant in adopting such kind of SC structure due to its negative impact on the dynamics (both order and inventory oscillation) of the SC. This is mainly because traditional inventory management models and ordering policies are not suitable in reverse logistics (Rogers and Tibben-Lembke, 2002). There is the need for practical managerial tools that support forward and reverse flows' integration in order to correctly implement reverse logistics, avoid poor operational performance, and encourage SC managers in adopting CLSC models (Stock et al., 2006). The goal of this paper is to answer to this call by developing a new order replenishment rule, which uses information from both backward and forward flows, and by evaluating the effects of such new rule on order and inventory instability.

We use a math model to describe reverse logistics (Rogers et al., 2012) and to design an $a d$ hoc-developed replenishment rule (R-APIOBPCS), conduct a number of numerical experiments and apply statistical analysis to investigate the impact of the factors that characterize a CLSC on order and inventory variance amplification. Finally, we highlight some important findings about the impact of reverse logistics on CLSC performance.

\section{Theoretical background}

Sustainability has been defined as "the potential for reducing long-term risks associated with resource depletion, fluctuations in energy costs, product liabilities, and pollution and waste management" (Shrivastava, 1995).

A sustainable supply chain (SSC) is defined as "a strategic and transparent integration of firms pursuing social, environmental and economics goals in the systemic coordination of key inter-organizational business processes for improving the long-term economic performance" (Carter and Rogers, 2008). Sustainable supply chain management (SSCM) is the management of material flows, information and funds, as well as cooperation between firms along the SC that simultaneously consider the three 
IJPDLM

43,7

566 dimensions of sustainable development, i.e. environmental, social and economic (Elkington, 2002; Seuring and Müller, 2008).

Finally, an interesting definition of "green supply chain management" is given by Srivastava (2007):

Integrating environmental considerations into supply chain management, including product design, research and selection of raw materials, production processes the delivery of the final product to the consumer, and product management at the end of its useful life.

In fact, one of the problems of greatest interest to the recent literature concerns the management of products at the end of their useful life. EU legislation has highlighted the importance of products recovery and recycling. Between 1990 and 1995, the amount of waste generated in Europe increased by 10 per cent, and by 2020, the Organisation for Economic Cooperation and Development (OECD) estimates we could be generating 45 per cent more waste than 1995 . The 67 per cent of end-of-life products is either burnt in incinerators, or dumped into landfill sites. Both these methods create environmental damage, taking up more and more valuable land space, but it also causes air, water and soil pollution. (http://ec.europa.eu/environment/waste/index.htm).

Directive 2008/98/EC sets the basic concepts and definitions related to waste management, such as definitions of waste, recycling, and recovery. Waste legislation and policy of the EU member states shall apply the waste management practices reported in Figure 1 according to a top-down priority order.

Moreover, there are three main complementary directives that require manufacturers, retailers, importers, exporters and consumers to participate in stringent requirements for the disposal of waste: Directive 2002/96/EC (waste electrical and electronic equipment (WEEE)) (European Parliament and Council, 2003); Directive 2002/95/EC (restriction of the use of certain hazardous substances (RoHS) in electrical and electronic equipment); Directive 2000/53/EC (end of life vehicles (ELV)).

The scientific community has demonstrated a growing interest in the subject of green SC management and, specifically, in a relatively new structure of SC, the so-called "CLSC", designed to manage the recycling and recovery process of end-of-life products. The recovery process consists of several highly inter-related sub-processes: product acquisition, reverse logistics, inspection and disposition, reconditioning and distribution
Figure 1.

The waste management hierarchy proposed by EU

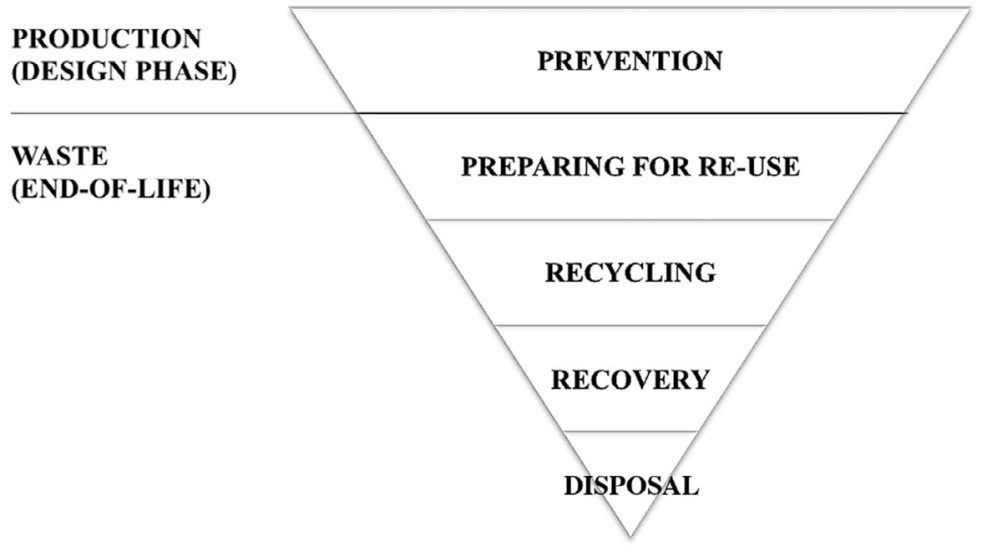


and selling of the recovered products (Ait-Kadi et al., 2012; Guide and Van Wassenhove, 2002). Basically, the key element in all definitions and discussions of reverse logistics is the movement of something from its end-user to some other activity or location, usually after its intended utility is fully or partly consumed (Haas et al., 2003).

A simple conceptual model of reverse logistics (Srivastava, 2008) considers the customers as the sources of product returns to collection centres. From collection centres, used products can be shipped to two distinct rework sites: repair and refurbishing centres (that repair/refurbish goods in order to make them almost "as good as new") and remanufacturing centres (produce upgraded remanufactured goods). All the returned goods are resold in primary or secondary market after necessary disposition. Figure 2 shows the basic flow diagram of reverse logistic activities. We use different graphical elements for representing forward SC activities, backward SC activities, and storage activities (inventories). Storage activities were added to the Srivastava (2008) model because of their relevance to the topic of the present paper.

\section{Problem statement}

Although reverse logistics increases the total cost of ownership (Tibben-Lembke, 1998), benefits of adopting reverse logistics and CLSC have been largely demonstrated in the literature. For example, economical sustainability of a CLSC has been assessed by Georgiadis and Besiou (2010) and greenhouse gas emission reduction in CLSC has been proved by Paksoy et al. (2011). Also, good reverse logistics practices can make a firm more competitive by reducing the customer's risk when buying a product (Rogers and Tibben-Lembke, 2001), and thus increasing the customer value (Russo and Cardinali, 2012).

However, Guide and Van Wassenhove (2002) find the companies that have been most successful with their reverse SCs are those that closely coordinate them with their

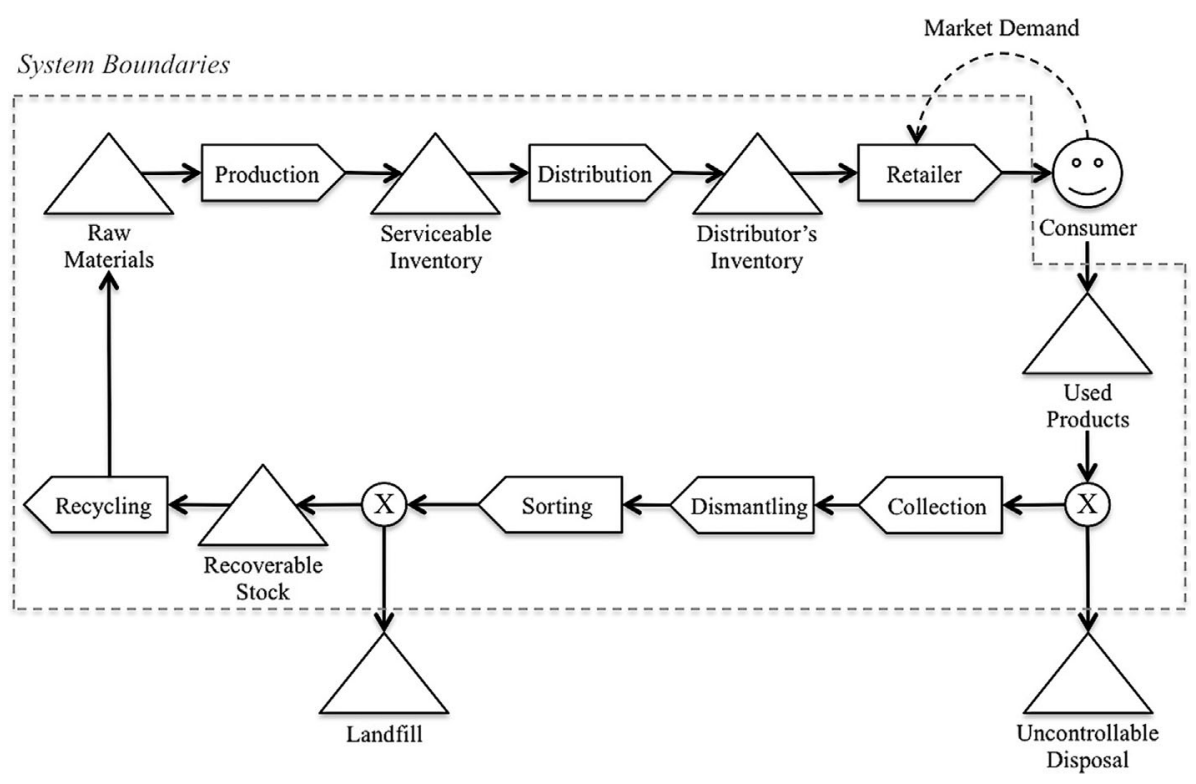

Source: Re-arranged from Srivastava (2008)
Impact of reverse logistics

567
Figure 2.

Basic flow diagram of reverse logistics activities 
IJPDLM

43,7

568 forward SCs. The relation between the forward and the reverse channels must be well designed, because reverse distribution may take place through the original network or can be delegated to third-party logistics. The same kind of issue has been highlighted by Nativi and Lee (2012), according to whom, the performance of the raw-material supplier will depend on the amount of inventory on-hand of the recycled-material supplier to fulfil the manufacturer's orders. Moreover, the growing complexity of supply networks and emerging supply arrangements, represented by CLSCs, provides unique opportunities to further investigate and test the development of audit tools through the recognition of the role of integration as a factor affecting performance (Mondragon et al., 2011). Finally, according to Jack et al. (2010), reverse logistics capabilities should include the internal and external connectivity of information flowing the SC. These capabilities represent a bundle of information-related processes that enable a firm to better manage its reverse logistics activities that may in turns relate to cost savings.

From a SC management perspective, the coordination and integration between forward and reverse flows can be achieved by designing proper order replenishment policies. However, existing order policies do not explicitly consider the flow of products remanufactured. Not considering information about the backward flow in the replenishment rule may bring inefficiencies in order and inventory management (Adenso-Diaz et al., 2012). Well-known examples of these kinds of inefficiencies are the bullwhip effect and inventory oscillation. The bullwhip effect mainly concerns the dynamic of the flow of orders (information flow) placed upward the chain and the flow of products (material flow) delivered downward the chain. The bullwhip effect produces much inefficiency that lets costs increasing up to 25 per cent (Lee et al., 1997), deteriorates profitability of 15-30 per cent, increases annual inventory holding costs of 33 per cent, and cost of capital of 13 per cent (Metters, 1997). Drivers of the bullwhip effect are still investigated due to its critical and negative effects on firm performance (Hussain and Drake, 2011).

Thus, although reverse logistics may bring benefits in terms of economic and green sustainability, and also customer value, SC managers could still be reluctant in adopting such kind of SC structure due to its negative impact on the dynamics (both order and inventory oscillation) of the SC. On the contrary, wisely managing returns means thinking about the returned goods not as costly mistakes but as products still waiting to be sold profitably, an opportunity to be exploited (Stock et al., 2002).

We thus argue that there is a need for practical managerial tools and information systems for integrating forward and reverse flows in order to correctly implement reverse logistics, avoid poor operational performance, and encourage SC managers in adopting CLSC models. The lack of reverse logistics information and management systems was found by Rogers and Tibben-Lembke (2001) in their empirical survey conducted over 150 managers with reverse logistics responsibilities. Analogously, as reported in the study of Russo and Cardinali (2012), the majority of the firms recognise the importance of the product returns process, but only in a few situations the firms actually adopt specific practices to manage them in a better way. Finally, according to Richey et al. (2005) the requisite managerial resources should be focused on developing innovative ways to handle returns.

As the achievement of efficiency goals is a key indicator of reverse logistics effectiveness (Daugherty et al., 2002), it is relevant to generate specific order policies for CLSC that explicitly consider the return of products in order to achieve high 
performance for SC. To do this we need to unambiguously define how the level of return of product should be embedded in the replenishment rule and synchronise the up-stream and downstream flows of material in SC.

Motivated by these considerations, the goal of this paper is twofold. On the one hand, the presented research aims at developing a new order replenishment rule, which takes into considerations both the flows (backward and forward); on the other hand, it aims at evaluating the effects of such rule on the order and inventory instability. The proposed rule is a modified version of the well-known "automatic pipeline inventory and order based production control system" (APIOBPCS), in which the value of target pipeline depends on the amount of end-of-life products to be remanufactured.

The goal of this paper in line with the research agenda for 2020 proposed by Daugherty (2011):

Our literature has examined environmental issues over the years particularly relating to reverse logistics, returns handling, and recycling. These continue to be prime issue for business [...] How can companies design products and manage inventories [...]?

\section{The CLSC model}

We choose to limit our analysis to a single-echelon system (Figure 3), because the analysis of more complex models on one hand allows obtaining a better representation of reality, but on the other side it introduces some difficulties to really understand which variables have a strong impact on the results. Specifically, we use a math model to describe a CLSC (Rogers et al., 2012). In our model a manufacturer places orders to an external raw materials supplier (with unconstrained capacity) and provides new products to the marketplace. A remanufacturer collects a $k$-percentage of used products from customers to make them "as good as new" and then reintroducing them on manufacturer's serviceable inventory. This simple model assesses us to focus over the dynamics of the main source of variance amplification. The propagation of the bullwhip effect upstream the chain, in fact, reaches the maximum value on the top of the chain, where the variance ratio can be more than 20:1 (Zhou et al., 2010).

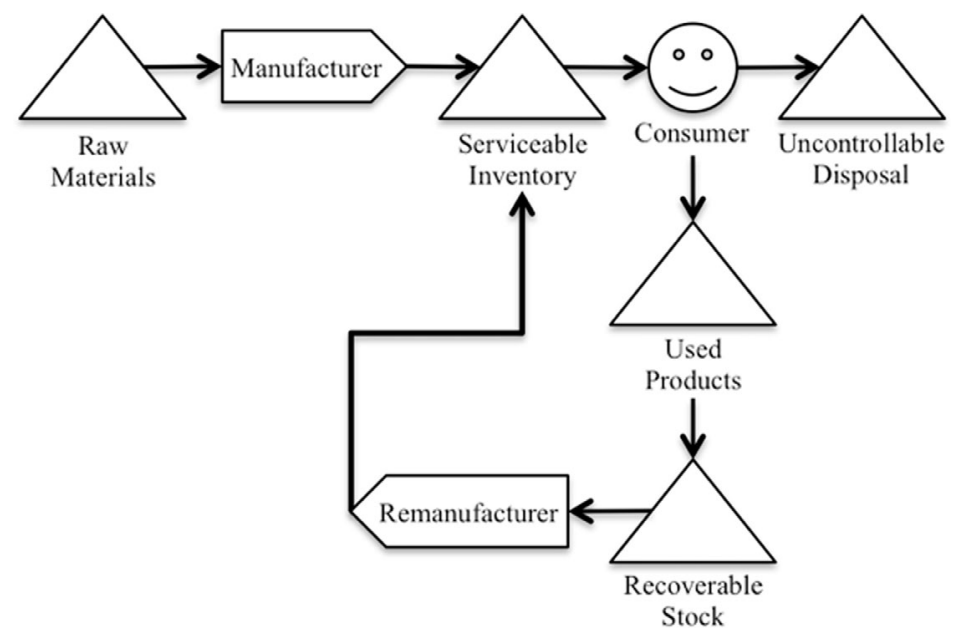

Figure 3. Flow diagram of a single-echelon CLSC 
IJPDLM

43,7

570
Therefore, smoothing the orders and the inventory variance of the first echelon can lead to an improvement of the general performance of a generic $i$-echelon CLSC.

Our research settings are quite similar to those of Zhou and Disney (2006). The authors analyse a simple CLSC to quantify variance ratios, highlighting the effect of a combined "in-use" and remanufacturing lead-time and the return rate on the order and inventory variance produced by the ordering policy. They use continuous time modelling as methodology and their model comprises a single-echelon CLSC with a remanufacturer that turns used products "as good as new". The demand pattern they suggest is a generic identically and independently distributed (i.i.d.) stochastic variable. They find that order and inventory variance is always less in CLSC than in SCs without returns of products. However, we found an interesting gap concerning the design on their order policy, which is used to model order replenishment in a CLSC. Therefore, we develop a proper order policy, which is suitable for CLSCs.

The main assumptions of the model are listed below:

- Customer demand. Zhou and Disney (2006) suggest that the demand should be a stationary, i.i.d. random process. According to Dejonckheere et al. (2003) we choose to set a "normally distributed" demand pattern;

- Forecast method. We adopt simple exponential smoothing (SES) technique (Disney and Lambrecht, 2008). The formula for SES is known to be $\hat{d}_{t}=\hat{d}_{t-1}+\alpha\left(d_{t-1}-\hat{d}_{t-1}\right)$, where the forecast made in the period $t$ is used by the manufacturer to estimate and place order at time $t$.

- Order policy. The replenishment rule adopted by the manufacturer is based on a forecast of future demand, the serviceable inventory level and the current work in progress (WIP). Here we use an evolved version of the traditional APIOBPCS order policy model (John et al., 1994), that can be expressed as:

[...] the quantity ordered is equal to the sum of forecasted demand plus a fraction $\left(1 / T_{i}\right)$ of the difference between the actual and target stock level of serviceable inventory plus a fraction $\left(1 / T_{w}\right)$ of the discrepancy between target and the actual WIP.

From the serviceable inventory, products are sold to the marketplace. Here we assume that the market demand can be fully satisfied without backlog. If the demand overcome the availability of the serviceable inventory we have stock-outs and lost demand. With this condition we guarantee non-negative inventory.

- Remanufacturing dynamics. Referring to the modelling assumptions of Zhou and Disney (2006), only a percentage $0 \leq k \leq 1$ of market sales can be collected in the reverse loop; the remaining $1-k$ quantity is hypothesized to be unusable or disposed to a landfill.

An important element of the remanufacturing loop is the time gap existing between the sale of products and the remanufacturing process. Before products become available for recycling, in fact, they are hold by customers and when the $k$ fraction of products is collected the remanufacturer spends time for the recovery process. We consider that this time gap can be modelled using a stochastic variable, in particular an "exponential distribution". The mean of the exponential distribution is equal to $T_{r}$ that is the sum of the time of use and the remanufacturing time.

The methodological approach we choose in this work is the continuous time approach (Simon, 1952; Forrester, 1961). This method let to consider the system at an 
aggregate level, leaving the analyst free to develop more accurate and complex simulation models. The solution of systems of differential equations can be performed through several mathematical software tools (Cannella and Ciancimino, 2010; Ciancimino et al., 2012). In this paper we use Vensim ${ }^{\circledR}$ platform and the Euler method for numerical integration of ordinary differential equations, with a time step equal to 0.25 .

In Table I we summarize the mathematical formalism of the SC configuration described in this paper when a traditional APIOBPCS model is adopted.

The metrics we use in this paper are listed below:

- Order variance ratio (OVrA) represents the variance amplification of orders upstream the chain (Cannella et al., 2013).

- Inventory variance ratio (IVrA) is necessary to control fluctuations in serviceable inventory that result in higher holding and backlog costs (Disney and Towill, 2003).

Specifically, the order variance amplification (OVrA) and the inventory variance amplification (IVrA) are measured through the ratios:

$$
O V r A=\frac{\sigma_{\text {output }}^{2}}{\sigma_{\text {demand }}^{2}} ; \quad I V r A=\frac{\sigma_{\text {Inventory }}^{2}}{\sigma_{\text {demand }}^{2}}
$$

where variance of output is the variance of order in the last echelon of the chain.

Demand forecast

$$
\hat{d}_{t}=\hat{d}_{t-d t}+\alpha\left(d_{t-d t}-\hat{d}_{t-d t}\right)
$$

Sales to market

$$
S_{t}=\min \left\{d_{t} ; I_{t}\right\}
$$

Inventory

$$
I_{t}=I_{t-d t}+d t\left(O_{t-T_{p}}+R_{t-T_{r}}-S_{t}\right)
$$

Work in progress

$$
W_{t}=W_{t-1}+d t\left(O_{t}-O_{t-T_{p}}\right)
$$

Order quantity

$$
\begin{aligned}
O_{t}= & \hat{d}_{t}+\left(\left(T I_{t}-I_{t}\right) / T_{i}\right)+\left(\left(T W_{t}\right.\right. \\
& \left.\left.-W_{t}\right) / T_{w}\right)
\end{aligned}
$$

Non-negativity condition of order quantity

$$
O_{t} \geq 0
$$

Target inventory

$$
T I_{t}=\hat{d}_{t}
$$

Target WIP

$$
T W_{t}=T_{p} \cdot \hat{d}_{t}
$$

Products returned

$$
R_{t}=k \cdot S_{t}
$$

Products returned condition

$$
0 \leq R_{t} \leq S_{t}
$$

Impact of reverse logistics . 
IJPDLM

43,7

572
The aim of the new order policy is to consider the reverse flow that characterizes a CLSC. In particular, from equation (3) it is evident that products that are collected in the reverse flow increase the level of serviceable inventory. However, no information about the reverse flow affects the pipeline. Not considering the products remanufactured in the pipeline lead the order policy ignoring that another flow of entities will enter in the system. As a consequence, the order replenishment rule overestimates the order quantity increasing the variability.

To avoid the above-mentioned problem, we propose to align the target WIP with the flow of products from the reverse loop. The target WIP, in fact, represents the products supplied to the manufacturer that must be in the pipeline to cover the logistics lead time. In our new model of APIOBPCS the target WIP is expressed as:

$$
T W_{t} \Rightarrow\left\{\begin{array}{l}
\hat{d}_{t} \cdot T_{p}-k \cdot \hat{d}_{t} \cdot T_{r} \\
\geq 0
\end{array}\right.
$$

From equation (11), we have two main outcomes:

(1) the terms we insert reduce the target pipeline according to the quantity of products that enter in the system from the reverse flow; and

(2) the target WIP can be equal to 0 .

We want to underline the importance of the latter proposition, because we can investigate which is the link between the three parameters and the target WIP. From equation (11):

$$
T W_{t}=0 \Leftrightarrow \hat{d}_{t} \cdot T_{p} \leq k \cdot \hat{d}_{t} \cdot T_{r} \Leftrightarrow k \geq \frac{T_{p}}{T_{r}}
$$

The equation (12) reveals that if $k$ is greater than the ratio of the two lead times, the R-APIOBPCS lead orders to be lower than in the classical APIOBPCS. Furthermore, when the logistics and manufacturing lead time is less than the $k$-percentage of the remanufacturing lead time, the cumulate demand in $T_{p}$ can be met with the products from the reverse flow and there is no need to have a forward pipeline to cover the periods between the moment at which an order is placed and the moment in which the order is received.

We propose a design of experiment to test the effects of the R-APIOBPCS policy on the inventory and order variance amplification. Specifically, we evaluate the impact of the proposed policy for different values of $T_{p}, T_{r}$ and $k$, i.e. for different settings of the closed loop model. To minimize the influence of other factors on the response, we refer to the case in which the inventory proportional controller is always equal to the WIP proportional controller (Deziel and Eilon, 1967; Cannella and Ciancimino, 2010). Setting $T_{i}=T_{w}$ gives some advantage for the experimental design, in particular, by reducing the dimensions of the problem and guaranteeing the solutions to be stable. In particular, we set $T_{i}=T_{w}=4$ as suggested by Dejonckheere et al. (2003).

\section{Experimental design and numerical results}

To fulfil the research objective, we adopt the design of experiment approach. DOE lets investigate which factors influence the performance of the SC. We initialize our model by setting parameters as follows: 
- the mean of the normally distributed market demand is set to 100 units/week, with a standard deviation of ten units;

- the exponential smoothing factor is set to 0.33;

- the initial value of inventory is set equal to the mean of demand;

- the initial value of WIP is set equal to the product of the mean of demand and the manufacturing lead time;

Impact of reverse logistics

573

- the initial flow of products collected in the reverse loop is equal to the product of mean of demand and $k$; and

- the numerical experiments are performed for a time length $T=1,000$. This to overcome any transitory effect and initial instability of the system.

We are interested in exploring the influence of those factors specifically characterizing the reverse logistics structure. Such factors are $k, T_{p}$ and $T_{r}$. Such factors and the corresponding levels are listed in Table II. We conduct ten replications for each experimental point. We obtain a total of $3^{3} \times 10=270$ simulations.

The levels of $k$ have been chosen looking at the statistics provided by European Commission on the waste level of electrical and electronic equipment in Europe. In particular, WEEE is currently considered to be one of the fastest-growing waste streams. The EU WEEE Directive, as we mention in the introduction section, strongly focuses on producer responsibility as a key policy mechanism for reducing the quantity of WEEE going to end disposal treatment facilities. Data are collected by the web service "Eurostat" (http://epp.eurostat.ec.europa.eu/). Among the member states, Germany has provided the most complete data from 2006 to 2008 (the last available year), summarized in Figure 4.

The average quantity of EE products recovered in Germany between 2006 and 2008 is approximately of 37 per cent. Given this empirical evidence, we can set the medium level of $k$ equal to 40 per cent, the low level equal to the recovery percentage of less virtuous member states ( 15 per cent) and the high value equal to the target imposed by the EU (70 per cent) (http://ec.europa.eu/environment/waste/index.htm).

After setting the factors levels, we perform a full factorial DOE and statistical analysis using Minitab statistical software, with a level of significance $\alpha=0.05$. The results are listed in Table III.

All the main factors and interactions are significant $(p$-value $<0.05)$. Figures 5 and 6 report the cumulate sum of squares of OVrA and IVrA, in order to highlight the factors with greater impact on performance.

Main results are:

- $O V r A$. The main factors responsible of more than 80 per cent of variance are the logistic and manufacturing lead time and the percentage of return flow.

\begin{tabular}{llccr}
\hline & & Level & & \\
Factor & Low & Medium & High & \\
\hline$k$ & 0.15 & 0.40 & 0.70 & Table II. \\
$T_{p}$ & 4 & 8 & 16 & Levels of the three factors \\
$T_{r}$ & 8 & 16 & 32 & under analysis \\
\hline
\end{tabular}




\section{IJPDLM 43,7}

\section{4}

Figure 4.

Data of WEEE in Germany (2006-2008)

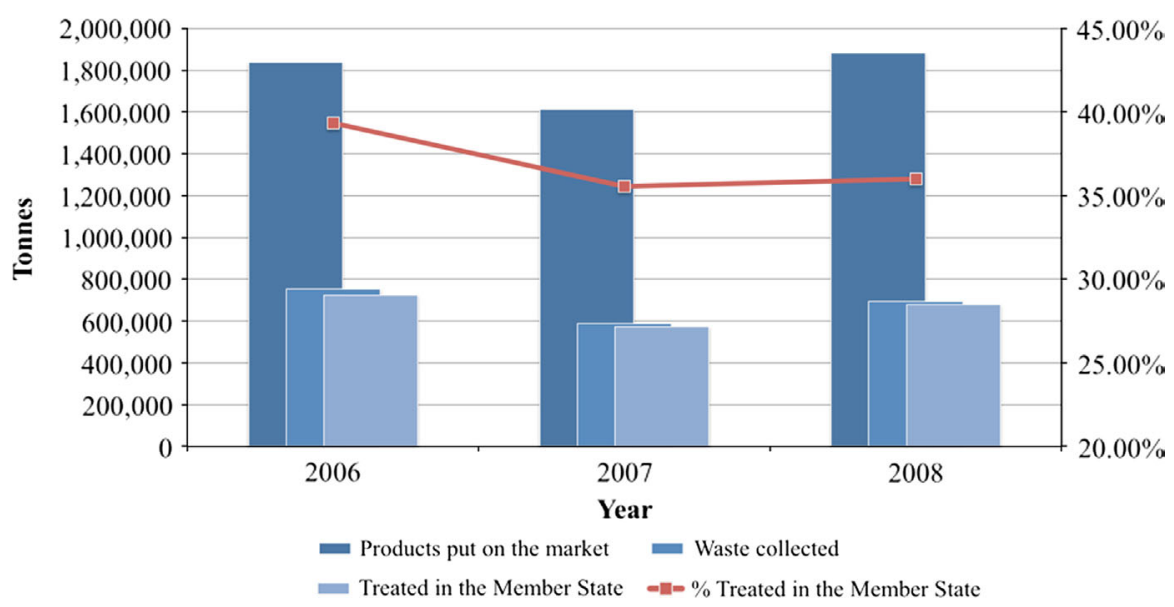

- IVrA. More than 80 per cent of variance can be explained by the main effects of the reverse loop lead time, the percentage of returns and the interaction among logistic and manufacturing lead time and the reverse loop lead time.

Figures 7 and 8 extend the analysis of the main effects.

From Figure 7 it can be noticed that when the two typical parameters of reverse flow increase their value from low to medium to high level, the order variance considerably decreases. It is not surprising that when the logistics and manufacturing lead time increases, the order variance increases (Chen et al., 2000).

With regard to IVrA, the effects of the main factors are contrasting. When $k$ goes from low level to the average, variance of the stock increases, while, when it passes from the mean level to high, variance decreases. The increase of $T_{r}$, instead, always involves an increase of the variance of the inventory.

The graphical representation of interactions between the factors is shown in Figures 9 and 10 .

To make easier the comprehension of interaction effects, in Table IV we report the effects of interactions on OVrA, while in Table V on IVrA. We set three levels to describe the effect: high $(\mathrm{H})$, when the interaction has a strong effect on reducing the order variance (Table IV) and inventory variance (Table V); medium (M), when the interaction produces an "average" effect; low (L), when OVrA (or IVrA) is slightly influenced by interaction. Such tables allow us to focus on those interactions that have the higher impact both on OVrA and on IVrA and, thus, give the best performance for the system under study.

In this analysis, IVrA and OVrA dramatically decrease when lead time parameters are at the lowest levels, and when $k$ is at the highest level. This result is aligned to Zhou and Disney (2006).

After having discussed the results obtained by our experimental design, we repeat the full experimental design for the model in which there is a traditional APIOBPCS order policy and we compare the results through a paired $t$-test under the hypothesis that the means of OVrA and IVrA in our model (R-APIOBPCS) are lower than the traditional approach with a confidence level of 0.05 . 


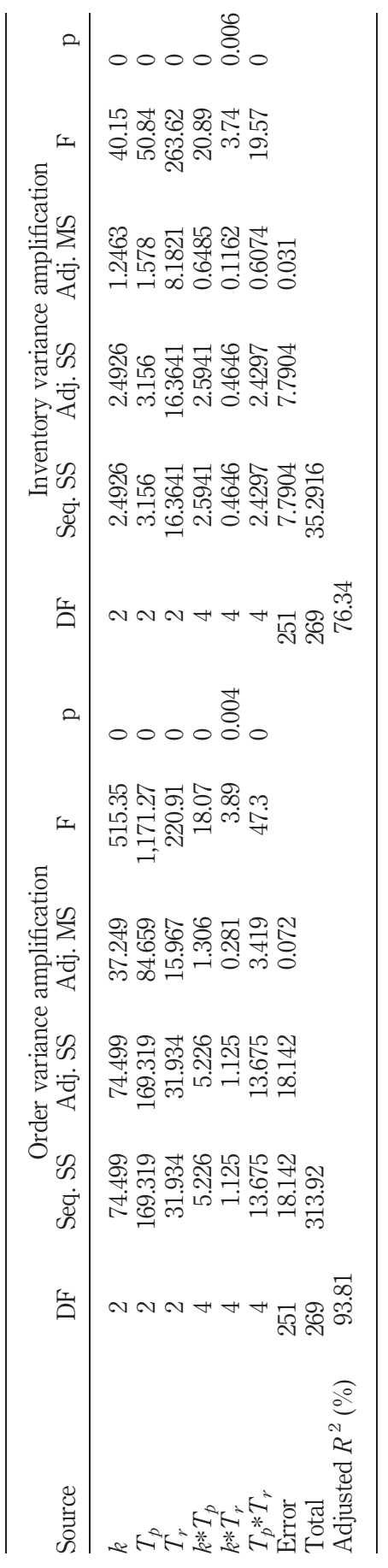

Impact of reverse logistics

575

Table III. Output of the general linear model for OVrA and IVrA 
IJPDLM

43,7

576

Figure 5.

Pareto chart of sum of squares for GLM results of OVrA
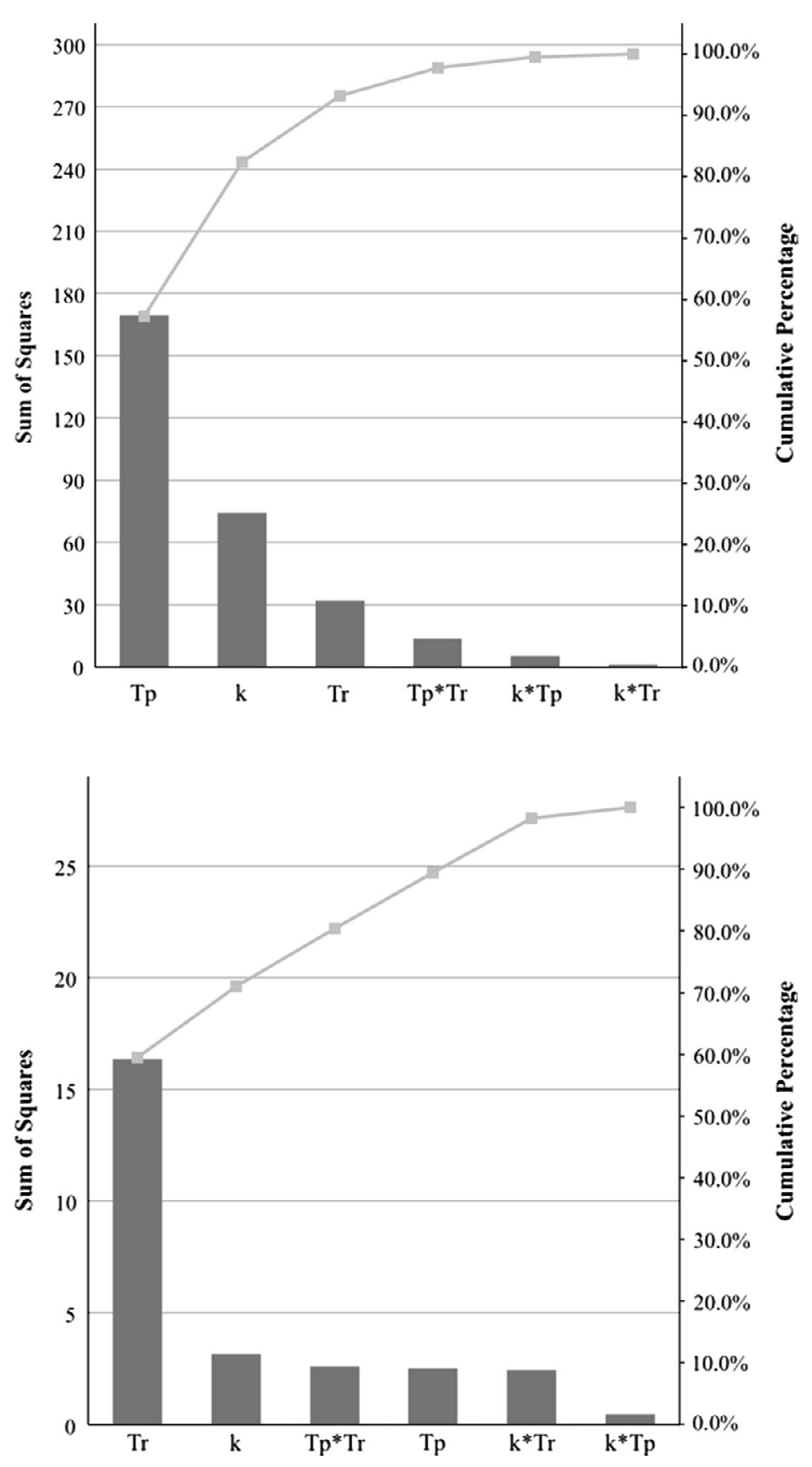

䢘
Figure 6.

Pareto chart of sum of squares for GLM results of IVrA 


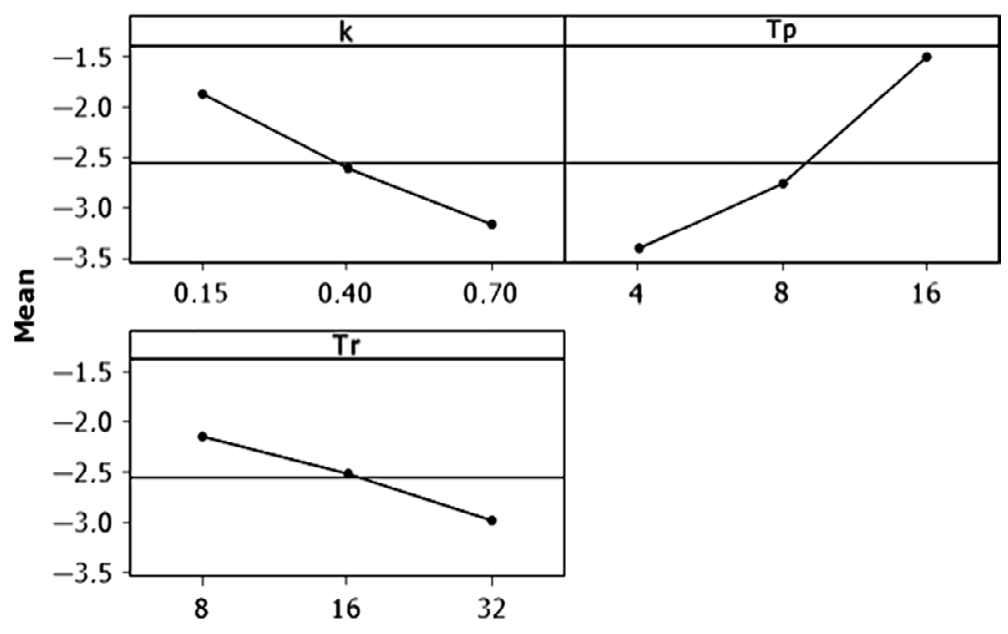

Impact of reverse logistics 577

Figure 7. Main effects of the factors considered on $\mathrm{OVrA}$

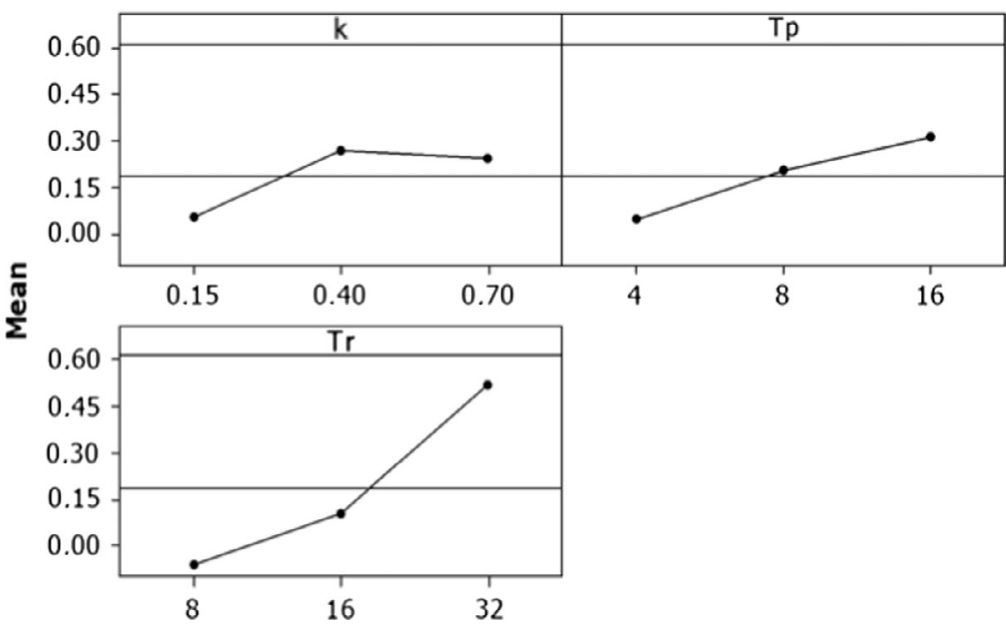

Figure 8. Main effects of the factors considered on IVrA

The results clearly demonstrate that $\mathrm{OVrA}$ is more than $2 \times$ lower (on average) that when a traditional APIOBPCS is adopted, while IVrA is, on average, $3 \times$ higher. We, thus, narrow our analysis to those experimental points in which the performance of the system is globally improved. Therefore, we extrapolate the data set of ten replications under the condition: $k=0.7 ; T_{p}=4 ; T_{r}=8$. We first test and verify that OVrA and IVrA under this experimental point are significantly lower than in the rest of the points (we use a two-sample $t$-test because of the different sample dimensions).

The second test compares the means of OVrA and IVrA using the proposed R-APIOBPCS model and the results obtained with the traditional APIOBPCS, measuring the outputs in the best conditions. In this scenario we can perform again a paired $t$-test, because we have the same number of replications in the same point. The results of the test clearly show that, in the best condition, the proposed modified 
IJPDLM

43,7

\section{8}

Figure 9.

Interactions of the factors considered on OVrA

Figure 10.

Interactions of the factors considered on IVrA
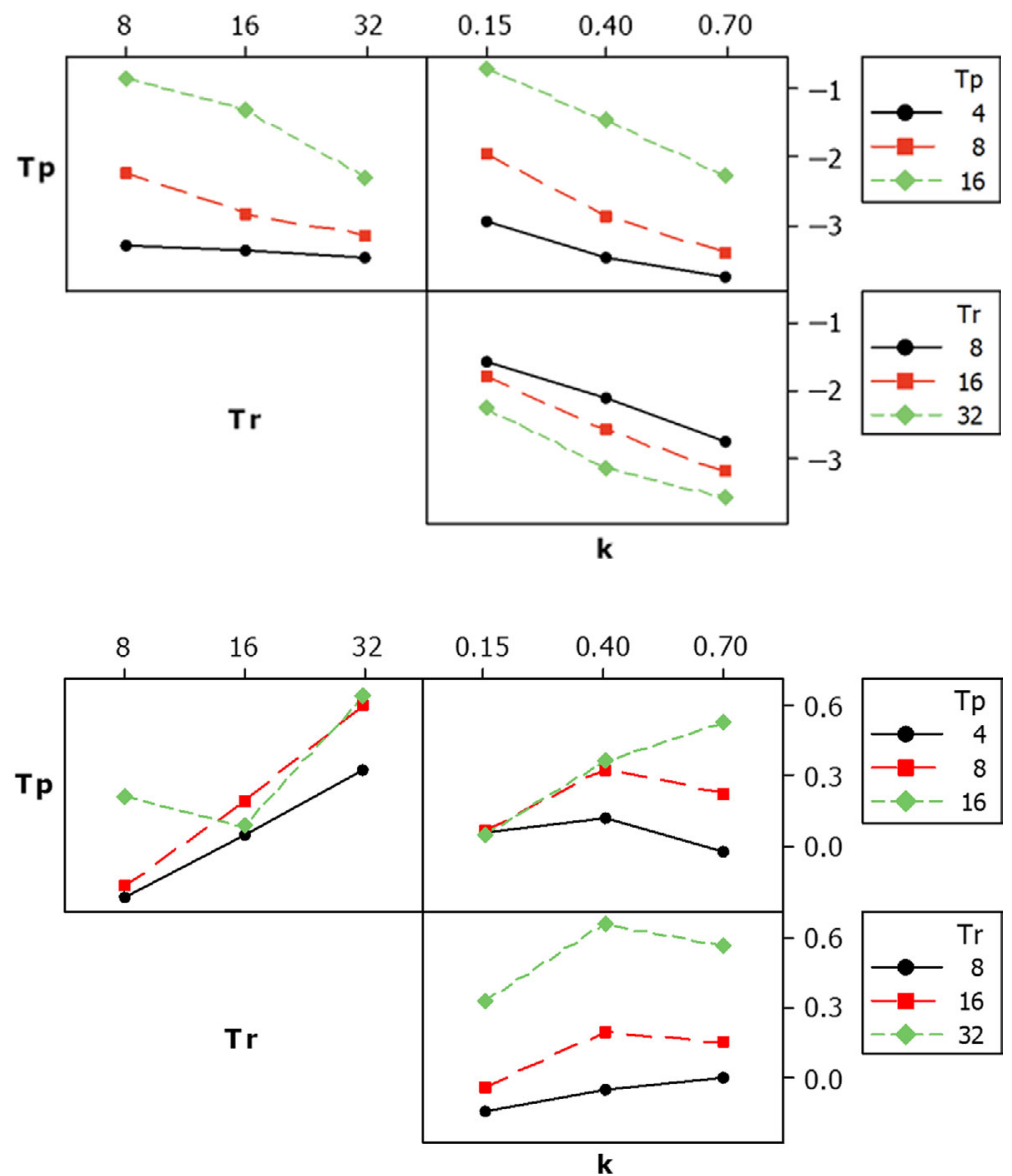

Table IV.

Effects of interactions of the factors on OVrA

\begin{tabular}{|c|c|c|c|c|c|c|c|c|c|c|c|c|}
\hline & & & $T_{p}$ & & & $k$ & & & & & $T_{p}$ & \\
\hline \multirow{4}{*}{$T_{r}$} & & $L$ & $M$ & $H$ & $L$ & $M$ & $H$ & \multirow{4}{*}{$k$} & & $L$ & $M$ & $H$ \\
\hline & $L$ & $\mathrm{H}$ & $\mathrm{M}$ & $\mathrm{L}$ & $\mathrm{L}$ & $\mathrm{M}$ & $\mathrm{M}$ & & $L$ & $\mathrm{M}$ & $\mathrm{M}$ & $\mathrm{L}$ \\
\hline & $M$ & $\mathrm{H}$ & $\mathrm{M}$ & $\mathrm{L}$ & $\mathrm{L}$ & $\mathrm{M}$ & $\mathrm{H}$ & & $M$ & $\mathrm{H}$ & $\mathrm{M}$ & $\mathrm{L}$ \\
\hline & $H$ & $\mathrm{H}$ & $\mathrm{H}$ & $\mathrm{M}$ & $\mathrm{M}$ & $\mathrm{H}$ & $\mathrm{H}$ & & $H$ & $\mathrm{H}$ & $\mathrm{H}$ & $\mathrm{M}$ \\
\hline
\end{tabular}

Table V.

Effects of interaction of the factors on IVrA

\begin{tabular}{|c|c|c|c|c|c|c|c|c|c|c|c|c|}
\hline & & & $T_{p}$ & & & $k$ & & & & & $T_{p}$ & \\
\hline \multirow{4}{*}{$T_{r}$} & & $L$ & $M$ & $H$ & $L$ & $M$ & $H$ & \multirow{4}{*}{$k$} & & $L$ & $M$ & $H$ \\
\hline & $L$ & $\mathrm{H}$ & $\mathrm{H}$ & $\mathrm{M}$ & $\mathrm{H}$ & $\mathrm{H}$ & $\mathrm{H}$ & & $L$ & $\mathrm{M}$ & M & $\mathrm{M}$ \\
\hline & $M$ & $\mathrm{M}$ & $\mathrm{M}$ & $\mathrm{M}$ & $\mathrm{H}$ & $\mathrm{M}$ & $\mathrm{M}$ & & $M$ & $\mathrm{M}$ & $\mathrm{L}$ & $\mathrm{L}$ \\
\hline & $H$ & $\mathrm{~L}$ & $\mathrm{~L}$ & $\mathrm{~L}$ & $\mathrm{~L}$ & $\mathrm{~L}$ & $\mathrm{~L}$ & & $H$ & $\mathrm{H}$ & $\mathrm{H}$ & $\mathrm{L}$ \\
\hline
\end{tabular}


APIOBPCS is capable to reduce the order and inventory variance amplification, respectively, of $2.1 \times$ and $1.6 \times$ respect to traditional APIOBPCS.

\section{Findings and contributions}

We summarize the main findings of this paper as follows:

- The existence of the backward flow positively impacts the order variance. Specifically, when the reverse flow increases the order variance decreases. We find that the backward flow performance depends not only on the percentage of products collected but also on the in-use and remanufacturing lead time. In particular, a higher $T_{r}$ lets order variance to be lower thanks to the effect on the target WIP.

- The traditional APIOBPCS is capable to control and reduce OVrA in a CLSC, but IVrA results higher than the traditional SC. In our opinion, this result is not surprisingly and it could be due to the sum of variability that influences the inventory. In the model, in fact, the serviceable inventory is affected by two main sources of variability: the customer demand and the flow of products collected by reverse logistics. The interaction of these two elements produces an increase on inventory variance.

- The R-APIOBPCS proposed in this work overcomes the limits of the traditional APIOBPCS and further reduces OVrA. IVrA further increases, because the proposed order policy gives more importance to the flow of collected end-of-life products. In fact, the variance of the reverse flow is higher than the variance of orders; as a consequence, if the reverse flow impacts more on supplying the serviceable inventory, even the variance of inventory will increase.

- Three parameters $\left(k, T_{r}\right.$ and $\left.T_{p}\right)$ can be optimized to obtain considerable improvements on SC performance. In particular, the levels that most influence $\mathrm{OVrA}$ and IVrA are the lowest for the two lead times and the highest for the percentage of products collected through the reverse loop. By adopting these levels we obtain a robust model and a significant reduction of IVrA and OVrA compared to the traditional APIOBPCS (Figures 11 and 12).

- The optimization of parameters still gives the best performance in real applications, i.e. when $k=40$ per cent. This important information can be extrapolated comparing Tables IV and V. In fact, setting $k=40$ per cent, the lowest values of IVrA and OVrA are achieved when setting at lowest values both $T_{r}$ and $T_{p}$. As operations consequence, the main way to achieve the best performance should be the minimization of both $T_{r}$ and $T_{p}$. Moreover, companies that adopt a closed loop structure should target to reach high level of $k$.

The findings of this paper provide implications and contributions to green $\mathrm{SC}$ management and reverse logistics literature. The most significant contribution of this paper to existing literature is the development and statistical testing of a novel order policy model that explicitly includes products collected by reverse logistics. This order policy takes its foundations from the well-known APIOBPCS model and includes a different structure of the target WIP. In particular, the proposed expression of the desired pipeline considers that demand-during-lead-time can be satisfied both with incoming items from the forward flow and with remanufactured products from the reverse flow. 


\section{IJPDLM}

43,7

580

Figure 11.

Orders placed during 50 weeks vs market demand
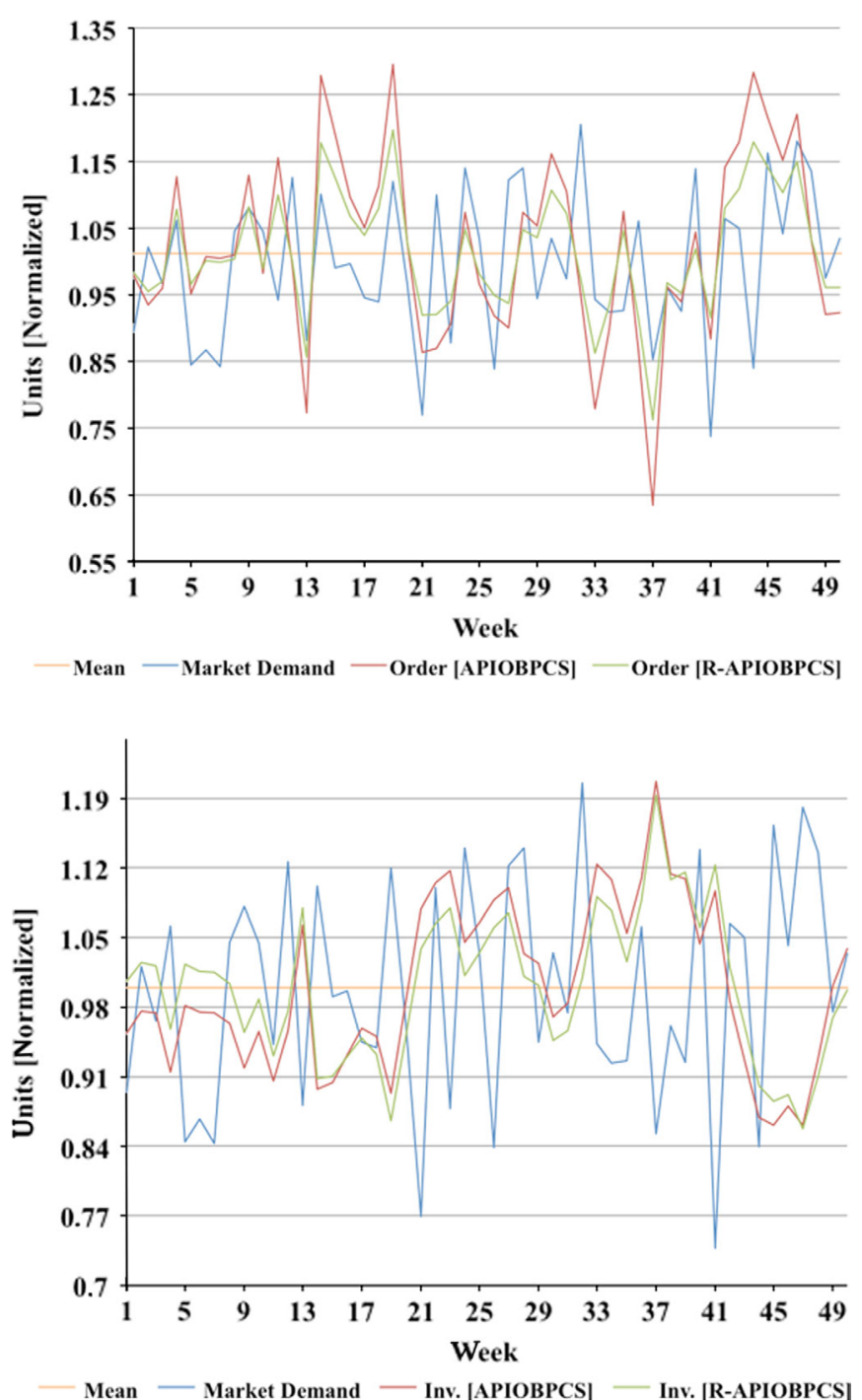

Figure 12.

Inventory levels during 50 weeks vs market demand

We believe that this paper offers three important implications for practice of logistics and SC managers:

(1) Managers should not use APIOBPCS order replenishment rule in reverse logistics. Thanks to the comparative analysis between such a classical order policy, largely adopted in practical application, and the novel order policy proposed in this paper, we were able to show how one of the most used order policy is not suitable to cope with the dynamics of modern and green SCs. To the extent of our knowledge, this logistics management issue has not received particular attention in the SC literature. Managers should also 
generalize such finding and consider that most of the operational inefficiencies related to reverse logistics implementation are due the unsuitability of existing order and inventory management tools.

(2) Managers should adopt ad hoc designed replenishment rules in reverse logistics. We have proposed and tested a novel replenishment rule (R-APIOBPCS) that accurately coordinates the upstream and downstream flows of information and material. As mentioned above, the majority of the firms recognise the importance of the product return processes, but only in a few situations companies actually adopt specific practices to manage them in a better way (Russo and Cardinali, 2012). The proposed order policy can be reasonably considered one of the advocated managerial tools for the proper management of reverse logistics. In other words, the proposed replenishment rule is a tangible tool that permits to implement lean and global SC strategies advocated by Mollenkopf et al. (2010), as it allows SC dynamics stabilisation, by reducing inventory and limiting the variability of the orders placed to suppliers in SC with reverse logistics. Managers should also generalize such finding and consider that most of the operational inefficiencies due to reverse logistics implementation might be overcome by designing ad hoc order and inventory management tools.

(3) Logistics and SC managers should have a better knowledge concerning how the dynamics of CLSC impact on operational performance. This work suggests managers to consider placing fewer (or even no) orders to suppliers if the expected flow of remanufactured products is enough to satisfy demand during lead-time. Basically, we found that satisfying demand with the reverse flow is more convenient. This result complements the current knowledge and literature that tend to emphasize the importance of adopting CLSC solutions merely in terms of their benefit for the environment and, more in general, for sustainability. Indeed, we expect that managers are reluctant in adopting such kind of SC structure due to its negative impact on the dynamics. On the contrary, the comparative analysis presented in this paper clearly shows that a CLSC could be better of a traditional SC even in terms of operational performance.

We assume that these findings may motivate logistics and SC managers to implement CLSC when supported by innovative, suitable tools for the proper management of the information and material flow in the chain. Managers should be well acquainted that, by doing so, they not only satisfy national and international legislations but also achieve improvements in logistics performance.

\section{Conclusions}

The increasing importance of operations that allow "greening" the SC in managerial practices is mainly due to the EU legislation and the ambitious targets that European directives impose to companies.

Analogously, the interest on the topic of sustainability on operations is drastically increasing in the scientific literature. Among many research areas within sustainable operations, this paper focuses on reverse logistics and its impact on SC performance. We provide evidence that adopting a closed loop structure with reverse logistics can be economical profitable. In fact, collection of end-of-life products leads to avoid the variance amplification of orders to supplier. Avoiding the bullwhip effect in the $i$-stage of 
IJPDLM 43,7

582 the chain means avoiding the variability of demand in the upstream flow of information, with improvements on stock and production variability and, as a consequence, on costs.

We propose a modified APIOBPCS order policy, the reverse APIOBPCS, which includes in the expression of the target pipeline products collected by reverse logistics. The impact of the proposed R-APIOBPCS on SC performance has been tested for different conditions and structures of the CLSC (percentage of products collected by reverse logistics and the in-use and remanufacturing lead time). The obtained results clearly show that all the factors and their interactions have a statistically significant influence on the order and inventory variance amplification. Furthermore, the results highlight the importance to increase the percentage of end-of-life product collected by reverse logistics so to avoid order variance amplification. Moreover, inventory variance amplification can considerably be reduced only if the two considered lead times reach low values.

This paper has some limitations. We have analysed the impact of reverse logistics on SC performance with a numerical approach, but we consider that, given the importance of the topic for real companies, an empirical analysis should be performed. The potential benefit of the proposed order policy needs to be validated also via the study of different SC structures and through its application to real case studies. We collected data from the statistics provided by European Commission on the waste level of electrical and electronic equipment in Europe because WEEE is currently considered to be one of the fastest-growing waste streams and because CLSC structures are quite compliant to electrical and electronic equipment industry.

Future researches should evaluate the impact of new forecasting techniques that include elements of reverse logistics. More specifically, in real markets the reverse flow is independent from the sales of a specific company, and it is impossible to have an a priori knowledge of $k$. New researches could fill this gap with new forecast rules that help managers to estimate and forecast the value of $k$.

\section{References}

Adenso-Dìaz, B., Moreno, P., Gutiérrez, E. and Lozano, S. (2012), "An analysis of the main factors affecting bullwhip in reverse supply chains", International Journal of Production Economics, Vol. 135, pp. 917-928.

Ait-Kadi, D., Chouinard, M., Marcotte, S. and Riopel, D. (2012), Sustainable Reverse Logistics Network: Engineering and Management, Wiley-ISTE, Hoboken, NJ, February.

Cannella, S. and Ciancimino, E. (2010), "On the bullwhip avoidance phase: supply chain collaboration and order smoothing", International Journal of Production Research, Vol. 48 No. 22, pp. 6739-6776.

Cannella, S., Barbosa-Povoa, A.P., Framinan, J.M. and Relvas, S. (2013), "Metrics for bullwhip effect analysis", Journal of the Operational Research Society, Vol. 64, pp. 1-16.

Carter, C. and Easton, P. (2011), "Sustainable supply chain management: evolution and future directions", International Journal of Physical Distribution \& Logistics Management, Vol. 41 No. 1 , pp. $46-62$.

Carter, C. and Rogers, D. (2008), "A framework of sustainable supply chain management: moving toward new theory", International Journal of Physical Distribution \& Logistics Management, Vol. 38 No. 5, pp. 360-387.

Chen, F., Drezner, Z., Ryan, J. and Simchi-Levi, D. (2000), "Quantifying the bullwhip effect in a simple supply chain: the impact of forecasting, lead times, and information", Management Science, Vol. 46 No. 3, pp. 436-443. 
Ciancimino, E., Cannella, S., Bruccoleri, M. and Framinan, J.M. (2012), "On the bullwhip avoidance phase: the synchronised supply chain", European Journal of Operational Research, Vol. 221 No. 1, pp. 49-63.

Daugherty, P.J. (2011), "Review of logistics and supply chain relationship literature and suggested research agenda", International Journal of Physical Distribution \& Logistics Management, Vol. 41 No. 1, pp. 16-31.

Daugherty, P.J., Myers, M.B. and Richey, R.G. (2002), "Information support for reverse logistics: the influence of relationship commitment", Journal of Business Logistics, Vol. 23, pp. 85-106.

Impact of reverse logistics

Dejonckheere, J., Disney, S., Lambrecht, M. and Towill, D. (2003), "Measuring and avoiding the bullwhip effect: a control theoretic approach", European Journal of Operational Research, Vol. 147 No. 1, pp. 567-590.

Deziel, D. and Eilon, S. (1967), “A linear production-inventory control rule”, The Production Engineer, Vol. 43, pp. 93-104.

Disney, S. and Lambrecht, M. (2008), "On replenishment rules, forecasting, and the bullwhip effect in supply chains", Foundations and Trends in Technology, Information and Operations Management, Vol. 2 No. 1, pp. 1-80.

Disney, S. and Towill, D. (2003), "On the bullwhip and inventory variance produced by an ordering policy", Omega, Vol. 31 No. 3, pp. 157-167.

Elkington, J. (2002), Cannibals with Forks: The Triple Bottom Line of 21st Century Business, Reprint edition, Capstone, Oxford.

European Parliament and Council (2003), Directive 2002/96/EC of the European Parliament and of the Council of 27 January 2003 on Waste Electrical and Electronic Equipment (WEEE).

Forrester, J. (1961), Industrial Dynamics, MIT Press, Cambridge, MA.

Georgiadis, P. and Besiou, M. (2010), "Environmental and economical sustainability of WEEE closed-loop supply chains with recycling: a system dynamics analysis", International Journal of Advanced Manufacturing Technology, Vol. 47, pp. 475-493.

Guide, V. and Van Wassenhove, L. (2002), "The reverse supply chain: smart manufacturers are designing efficient processes for reusing their products", Harvard Business Review, 22 February, pp. 25-26.

Haas, D.A., Murphy, F.H. and Lancioni, R.A. (2003), "Managing reverse logistics channels with data envelopment analysis", Transportation Journal, Vol. 42 No. 3, pp. 59-69.

Hussain, M. and Drake, P. (2011), "Analysis of the bullwhip effect with order batching in multi-echelon supply chains", International Journal of Physical Distribution \& Logistics Management, Vol. 41 No. 8, pp. 797-814.

Jack, E.P., Powers, T.L. and Skinner, L. (2010), "Reverse logistics capabilities: antecedents and cost savings", International Journal of Physical Distribution \& Logistics Management, Vol. 40 No. 3, pp. 228-246.

John, S., Naim, M. and Towill, D. (1994), "Dynamic analysis of a WIP compensated decision support system", International Journal of Manufacturing System Design, Vol. 1 No. 4, pp. 283-297.

Kleindorfer, P., Singhal, K. and Van Wassenhove, L. (2005), "Sustainable operations management", Production and Operations Management, Vol. 14 No. 4, pp. 482-492.

Lee, H., Padmanabhan, V. and Whang, S. (1997), "Information distortion in a supply chain: the bullwhip effect", Management Science, Vol. 43 No. 4, pp. 546-558.

Linton, J., Klassen, R. and Jayaraman, V. (2007), "Sustainable supply chains: an introduction", Journal of Operations Management, Vol. 25, pp. 1075-1082. 
IJPDLM

43,7

584
Metters, R. (1997), "Quantifying the bullwhip effect in supply chains", Journal of Operations Management, Vol. 15, pp. 89-100.

Mollenkopf, D., Frankel, R. and Russo, I. (2011), "Creating value through returns management: exploring the marketing-operations interface”, Journal of Operations Management, Vol. 29, pp. 391-403.

Mollenkopf, D., Stolze, H., Ueltschy, M. and Tate, W. (2010), “Green, lean and global supply chains", International Journal of Physical Distribution \& Logistics Management, Vol. 40 Nos 1/2, pp. 14-41.

Mondragon, A.E.C., Lalwani, C. and Mondragon, C.E.C. (2011), "Measures for auditing performance and integration in closed-loop supply chains", Supply Chain Management, Vol. 16 No. 1, pp. 43-56.

Nasr, N. and Thurston, M. (2006), "Remanufacturing: a key enabler to sustainable product systems”, 13th CIRP International Conference on Life Cycle Engineering, Leuven, pp. 15-18.

Nativi, J.J. and Lee, S. (2012), "Impact of RFID information-sharing strategies on a supply chain with reverse logistics operations", International Journal of Production Economics, Vol. 136, pp. 366-377.

Paksoy, T., Bektaş, T. and Özceylan, E. (2011), "Operational and environmental performance measures in a multi-product closed-loop supply chain”, Transportation Research Part E, Vol. 47, pp. 532-546.

Richey, R.G., Genchev, S.E. and Daugherty, P.J. (2005), "The role of resource commitment and innovation in reverse logistics performance", International Journal of Physical Distribution \& Logistics Management, Vol. 35 No. 4, pp. 233-257.

Rogers, D.S. and Tibben-Lembke, R.S. (2001), "An examination of reverse logistics practices", Journal of Business Logistics, Vol. 22, pp. 129-148.

Rogers, D.S. and Tibben-Lembke, R.S. (2002), "Differences between forward and reverse logistics in a retail environment”, Supply Chain Management: An International Journal, Vol. 7 No. 5, pp. 271-282.

Rogers, D.S., Melamed, B. and Lembke, R.S. (2012), "Modeling and analysis of reverse logistics", Journal of Business Logistics, Vol. 33 No. 2, pp. 107-117.

Rubio, S., Chamorro, A. and Miranda, F.J. (2008), "Characteristics of the research on reverse logistics (1995-2005)", International Journal of Production Research, Vol. 46 No. 4, pp. 1099-1120.

Russo, I. and Cardinali, S. (2012), "Product returns and customer value: a footware industry case", in Jodlbauer, H., Olhager, J. and Schonberger, R.J. (Eds), Modelling Value, Contributions to Management Science, Part 2, Springer, Berlin, pp. 79-97.

Schneider, F., Kallis, G. and Martinez-Alier, J. (2010), "Crisis or opportunity? Economic degrowth for social equity and ecological sustainability. Introduction to this special issue", Journal of Cleaner Production, Vol. 18, pp. 511-518.

Seuring, S. and Müller, M. (2008), "From a literature review to a conceptual framework for sustainable supply chain management", Journal of Cleaner Production, Vol. 16, pp. 1699-1710.

Shrivastava, P. (1995), "The role of corporations in achieving ecological sustainability", The Academy of Management Review, Vol. 20, pp. 936-960.

Simon, H. (1952), "On the application of servomechanism theory to the study of production control”, Econometrica, Vol. 20 No. 2, pp. 247-268. 
Skinner, L., Bryant, P. and Richey, R. (2008), "Examining the impact of reverse logistics disposition strategies", International Journal of Physical Distribution \& Logistics Management, Vol. 38 No. 7, pp. 518-539.

Srivastava, S. (2007), "Green supply-chain management: a state-of-the-art literature review", International Journal of Management Reviews, Vol. 9, pp. 53-80.

Srivastava, S. (2008), "Network design for reverse logistics", Omega, Vol. 36, pp. 535-548.

Stock, J., Speh, T. and Shear, H. (2002), "Many happy (product) returns", Harvard Business Review, Vol. 80 No. 7, pp. 16-17.

Stock, J., Speh, T. and Shear, H. (2006), "Managing product returns for competitive advantage", MIT Sloan Management Review, Vol. 48 No. 1, pp. 57-62.

Tahvonen, O. (2000), Economic Sustainability and Scarcity of Natural Resources: A Brief Historical Review, Resources for the Future, Washington, DC, pp. 1-15.

Tibben-Lembke, R.S. (1998), "The impact of reverse logistics on the total cost of ownership", Journal of Marketing Theory and Practice, Vol. 6 No. 4, pp. 51-60.

Zhou, L. and Disney, S. (2006), "Bullwhip and inventory variance in a closed loop supply chain", OR Spectrum, Vol. 28, pp. 127-149.

Zhou, L., Disney, S. and Towill, D. (2010), "A pragmatic approach to the design of bullwhip controllers”, International Journal of Production Economics, Vol. 128, pp. 556-568.

\section{Corresponding author}

Manfredi Bruccoleri can be contacted at: manfredi.bruccoleri@unipa.it

To purchase reprints of this article please e-mail: reprints@emeraldinsight.com Or visit our web site for further details: www.emeraldinsight.com/reprints 